\title{
Design in China/Design for Chinal Made in China: 3 formas de ver el diseño de producto en el mercado chino
}

Nong Ru Cheng Lee ${ }^{1}$

RECIBIDO: 21.02.2016 / ACEPTADO: 26.03.2016

\begin{abstract}
Resumen
El artículo explora diferentes aspectos del diseño de producto en China, para ofrecer una visión global de este particular mercado asiático. Primeramente se observa cómo en los últimos años se han producido nuevas incorporaciones de ciudades chinas a los eventos de la Semana de Diseño, y cómo los productos diseñados en China han adquirido más presencia en eventos internacionales. Posteriormente se estudian los cambios en las pautas del consumo social, y finalmente nos adentramos en un análisis de las tendencias a través de productos premiados por China Good Design.
\end{abstract}

Palabras clave: diseño de producto, Hecho in China, tendencias, competitividad, globalización.

\section{Design in China/Design for China/Made in China: 3 ways to see product design in Chinese market}

\section{Abstract}

The article explores different aspects of product design in China, to provide an overview of this particular Asian market. Firstly, we focus on how new Chinese cities have joined the events of the Design Weeks in recent years and how Chinese products have attained more visibility in international events; Later, we study the changes in the patterns of social consumption, to delve finally into an analysis of trends through the products awarded with China Good Design.

Keywords: product design, Made in China, trends, competitiveness, globalization.

La semana de diseño de Milán, uno de los eventos más importantes en suelo europeo, celebra su edición anual en la cuidad de la moda y del diseño, donde no faltan grandes marcas europeas que exhiben sus productos. La asociación World Design Week también estuvo en el evento, y organizó varias presentaciones para fomentar los actos y las celebraciones relacionados con el mundo de diseño en diferentes ciudades del mundo. Curiosamente, entre todas las ciudades que celebran la semana del diseño se incorporaron varias chinas a la lista y gozaron de muy buena acogida. Además, la Design Week de Xiamen estuvo en el Sino-European Innovation Center promocionando la ciudad y el diseño Made in China. 

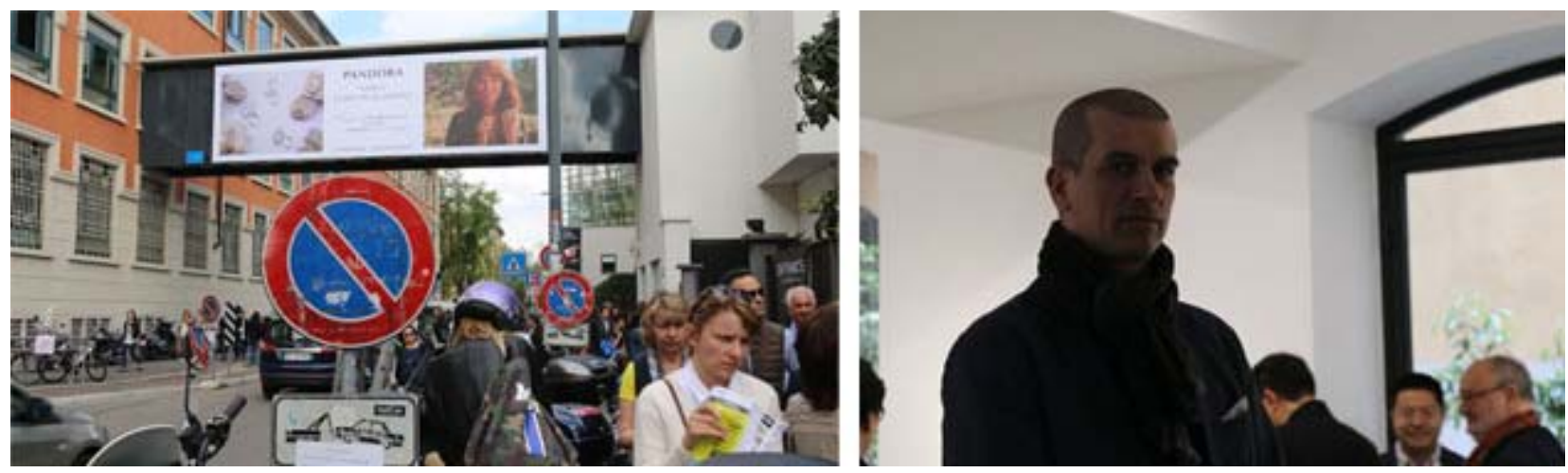

Fig. 1 (izda). El animado ambiente en la zona Tortona de Milán durante la Semana del Diseño.

Fig. 2 (dcha). Aleksandar Tatic, de Tatic Designstudio en Milán, invitado del evento Sino-European Innovation Center.

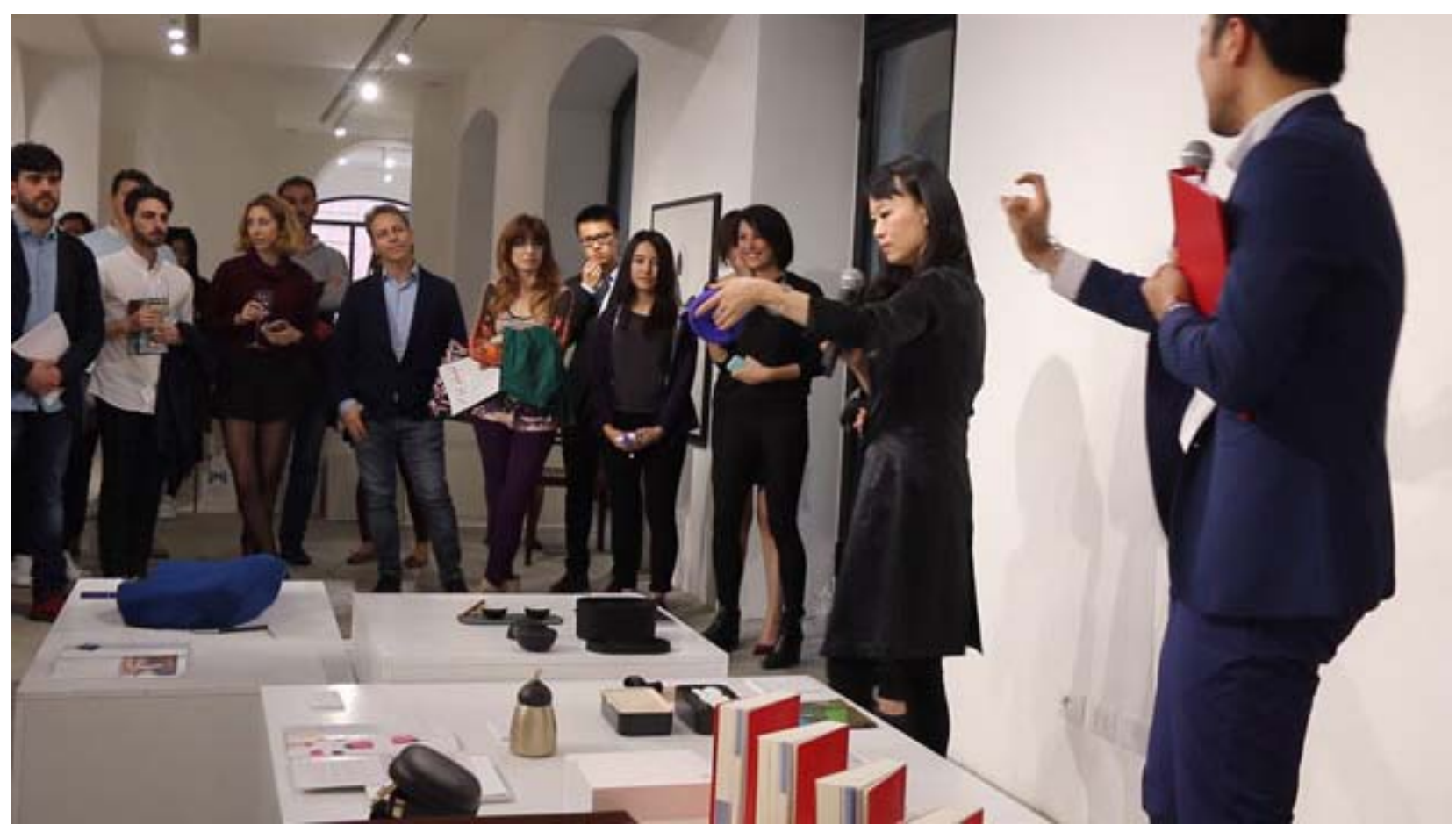

Fig. 3. China promociona sus diseños y sus eventos durante la Semana del Diseño de Milán.

Cuando hablamos de diseño industrial, siempre volvemos la mirada hacia ciudades europeas como Milán o Barcelona. China, con la reforma de la economía en 1978, es ahora la segunda del mundo y la mayor base de fabricación del mundo. Pero no hace mucho, el diseño en el mercado chino, era todavía un concepto ajeno. La mayoría de los fabricantes enfocaban su modelo del negocio a producir para vender a firmas internacionales, siguiendo el plano de fabricación de los diseñadores occidentales. Los productos fabricados en China tenían mala fama, por su calidad y su diseño más conservador y estéticamente poco atractivo. Por otro lado, en su mercado nacional los fabricantes enfocaban su modelo de negocio en copiar diseños existentes o productos europeos exitosos, y nadie se preocupaba de producir nuevos diseños. El término "Made in China" a menudo se refería a la copia o al producto de baja calidad.

\section{De maker a designer}

Ya en 2009, el informe de Bain \& Company mostraba el potencial chino en el consumo del mercado 
de productos de lujo. Tal como lo predijo, en 2011 se convirtió en el mayor consumidor del sector. Sin embargo, el nuevo presidente Xi y el repentino cambio de dirección política, en relación con el tratado sobre productos de lujo, provocaron un retroceso y se retomó el concepto de consumo tradicional del pueblo chino. La llegada de Xi a la presidencia hace que se retomen los valores tradicionales en pleno desarrollo económico.

El pueblo chino, que siempre ha hecho honor a su fama de trabajador y ahorrador, abrazó, con el despliegue económico, un nuevo mercado en que el producto del lujo pronto se convirtió en sinónimo de la prosperidad y de estatus social. La compra frenética de bolsos o zapatos italianos de las grandes pasarelas, de coches deportivos, de joyas y relojes valiosos, hizo que el mercado del sector duplicara su crecimiento cada año y la confianza ciega hacia grandes marcas europeas fomentó un consumo impulsivo y poco meditado, sin pensar en la funcionalidad ni en la relación precio-calidad, quizá por la sencilla razón de que el producto de lujo consigue fácilmente destacarle entre los demás.

No resulta sorprendente que el presidente Xi, que ya en 1999 fue nombrado gobernador de la provincia de Fujian, una de las provincias con más fábricas de textil e industria de accesorios y vestimentas, propusiese poco después de tomar posesión de su cargo en 2014 un cambio de enfoque sobre los productos de lujo extranjeros. Por un lado, presiona con impuestos y política al mercado; por el otro, promueve "el consumo inteligente": en vez de comprar productos de marcas caras elegir productos de diseño que mejoren la funcionalidad y ofrezcan originalidad, satisfaciendo así el deseo del consumidor de adquirir un producto único y a la vez con buena relación calidadprecio.

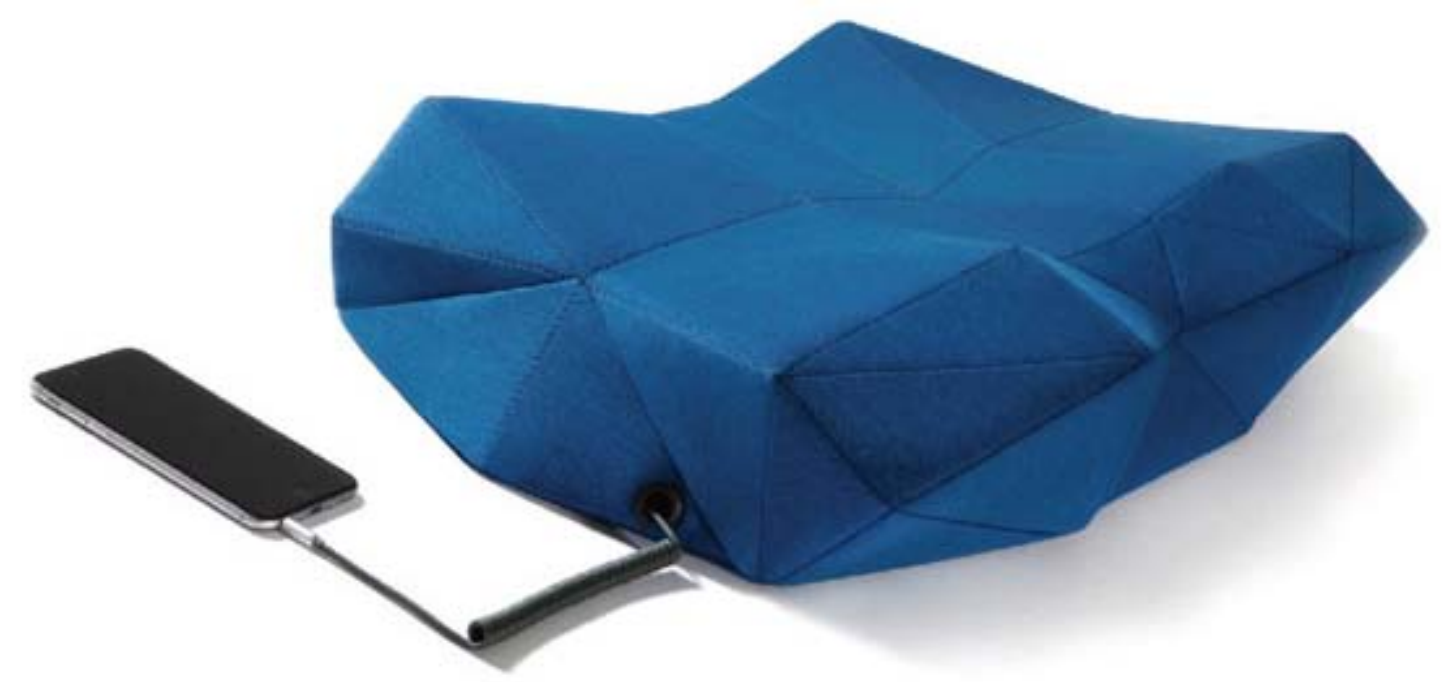

Fig. 4. Pilo. Fabricado y diseñado por Soundario Inc. China. La almohada Pilo redefine la almohada en cuanto a la forma, la textura y la función. Su apariencia geométrica transmite dureza pero el tacto es suave y esponjoso. Junto con la aplicación, la almohada también puede reproducir audio para favorecer el sueño. El exterior de Pilo está diseñado tanto por ingenieros biomédicos como por diseñadores industriales. 
En el campo de la electrónica, China antes era conocida como el principal fabricante de productos terminados, como fábrica de ensamblaje para las marcas internacionales. Ahora, sin embargo, ha adquirido suficiente conocimiento y experiencia para abrir su propio mercado en el sector de la electrónica, audio y sonido, Smartphone, etc. Marcas tales como XIAOMI o HUAWEI son fabricadas y diseñadas en China, cada vez con más presencia en nuestros mercados. Ahora, una vez que han conseguido estabilidad y confianza en el mercado internacional, necesitan una voz. La búsqueda de un lenguaje visual propio y la transformación del "Made in China" en "Diseñado en China" es el principal reto para elevar la competitividad de los productos chinos y el desarrollo de la industria creativa es la clave para el éxito. Las empresas chinas se ven en la urgente necesidad de hacer diseños creativos de talla mundial, por lo que es esencial crear eventos como la Semana del Diseño para proporcionar plataformas de diálogos y comunicación entre empresas y diseñadores.

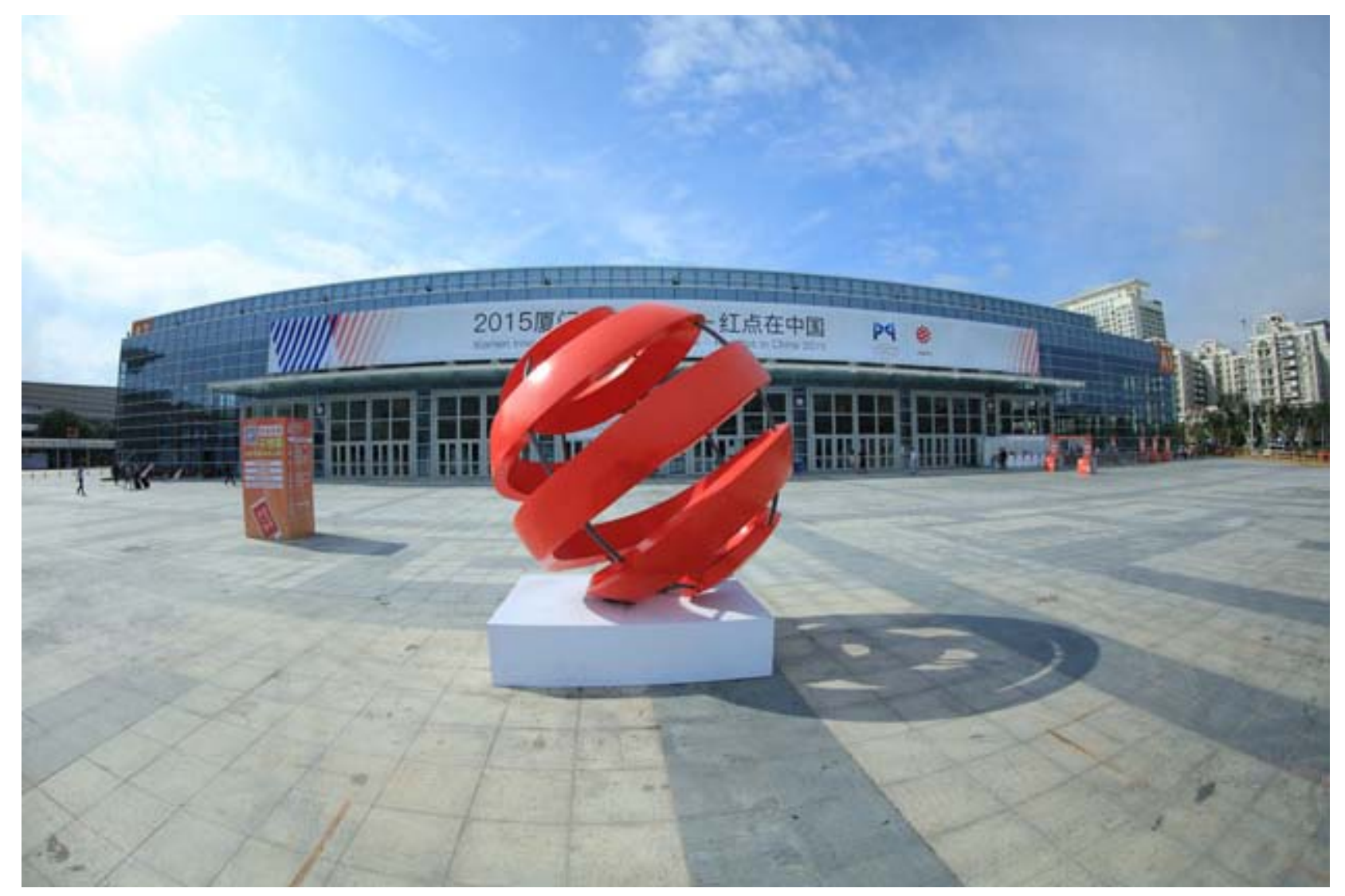

Fig. 5. Red Dot Design Award establece su oficina en Xiamen. 2014. 


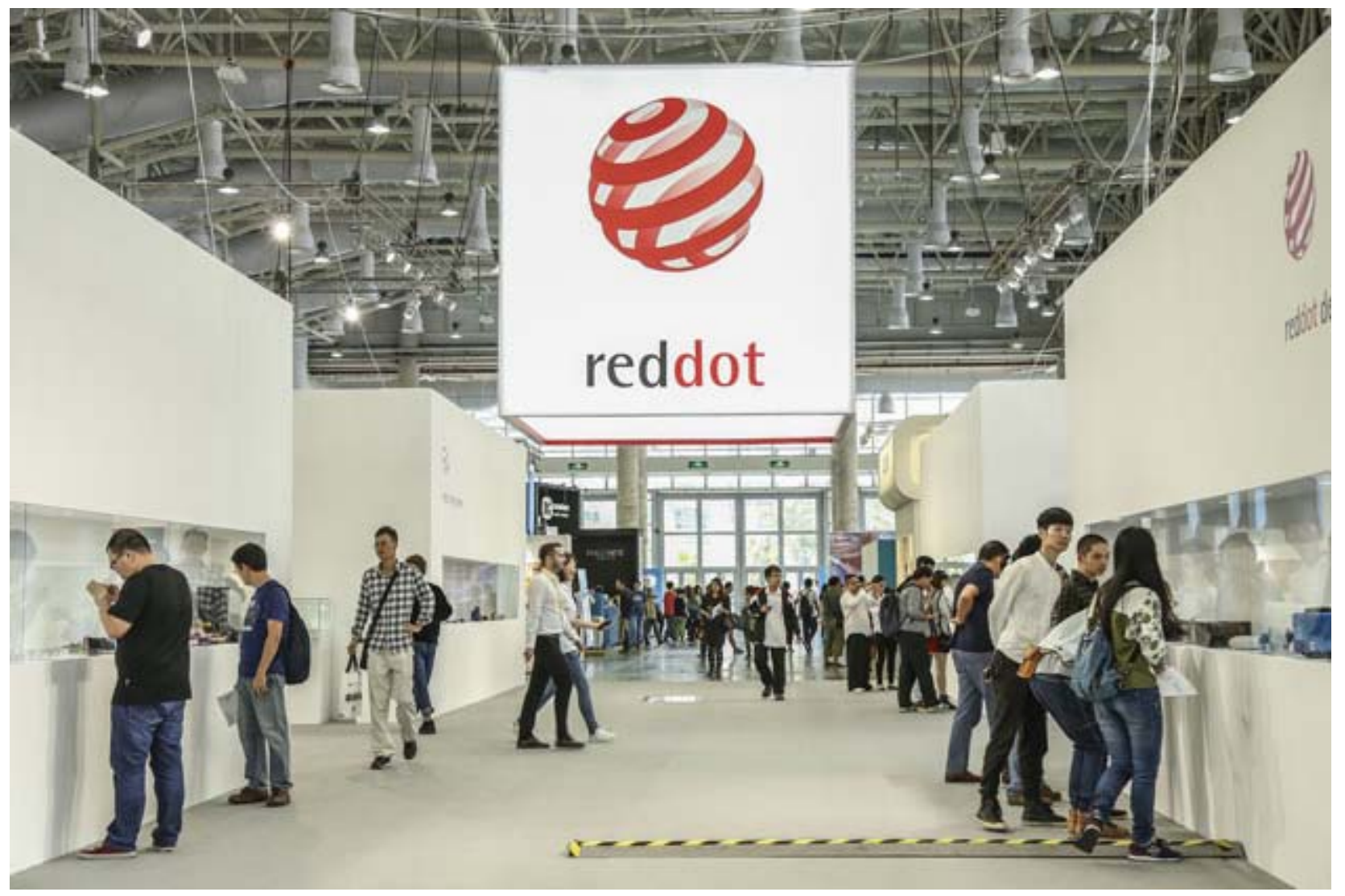

Fig. 6. Red Dot lleva el mundo del diseño de producto a la metrópoli del sur de China Xiamen: Red Dot es el principal socio y organizador de la Semana Internacional del Diseño de Xiamen, 2014.

\section{La redefinición de la tradición}

Durante la primera década de este siglo, la difusión masiva del smartphone cambió las costumbres de la mayoría de la gente. Como si de una navaja suiza se tratase, cada vez usamos menos utensilios, porque éste lleva en sí incorporadas múltiples funciones que sustituyen otros aparatos, alarmas, bloc de notas, linterna... En la tradición china, utilizar diferentes utensilios, y la relación entre el hombre y la herramienta, constituye en sí un acto ceremonial. La ceremonia del té, donde se utilizan varias teteras y tazas para regular la temperatura y conseguir el sabor y el color perfecto de cada sorbo, el código de los colores de las tradicionales lámparas de papel, o de los diferentes pinceles y cuencos de tinta para la caligrafía... Todos estos utensilios se reducen ahora a la mínima expresión para acomodarse a la vida moderna. La búsqueda de la calidad de vida en el tiempo moderno significa un retorno y una redefinición de la tradición. En el diseño de producto hay una tendencia a diseñar de nuevo, diferentes herramientas para cada funcionalidad. 


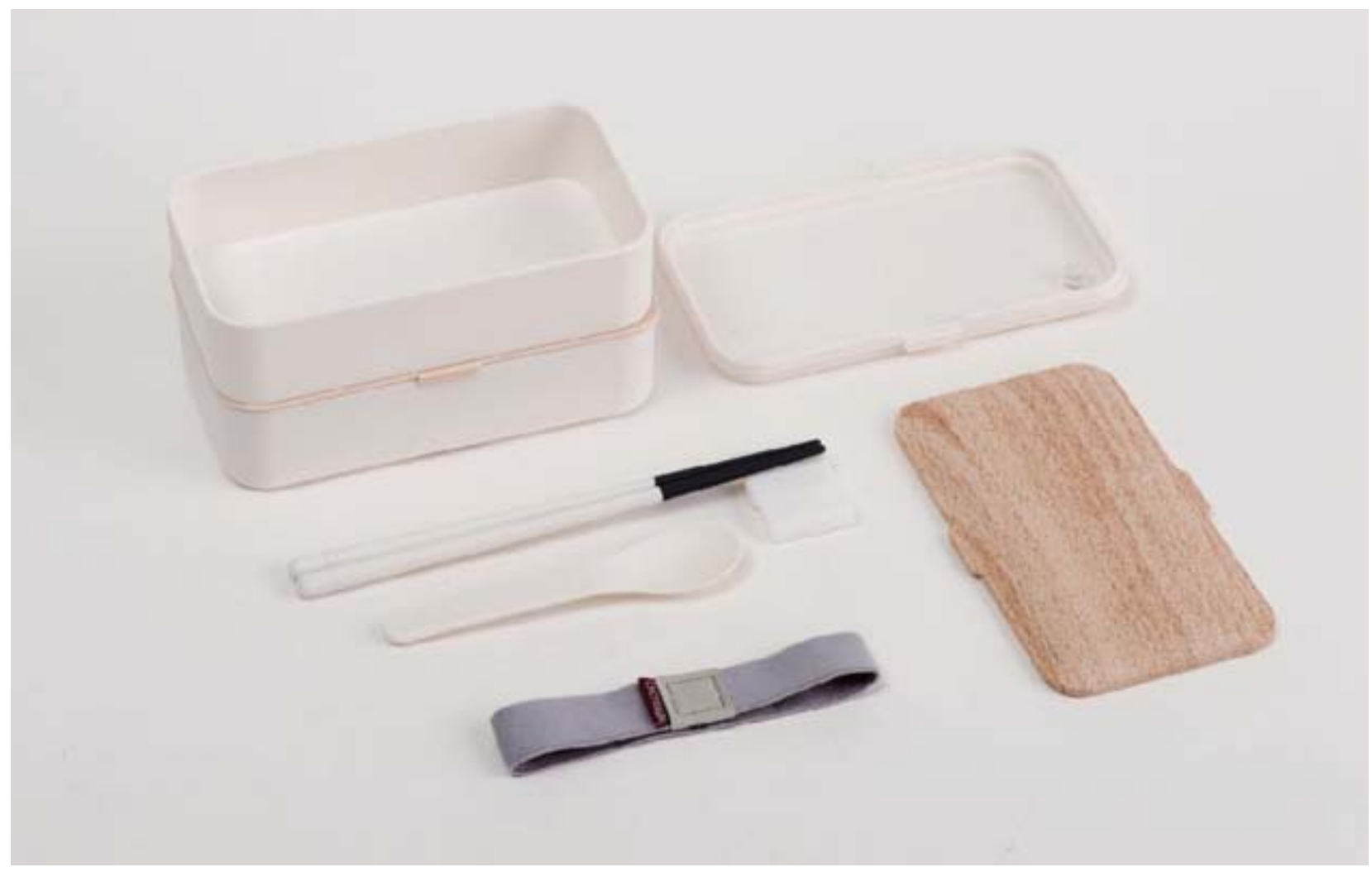

Fig. 7. Lunchbox Purity Nature. Fabricado por Xiamen Guanhua Xingye Industry \& Trade Co. Ltd. China. Diseñado por Chen Junfeng, China. El lunchbox "Purity Nature" utiliza los colores blanco y negro para dar sensación de textura de cerámica y madera. Dispone de varios compartimentos para separar alimentos y gestionar la cantidad que se desea llevar.

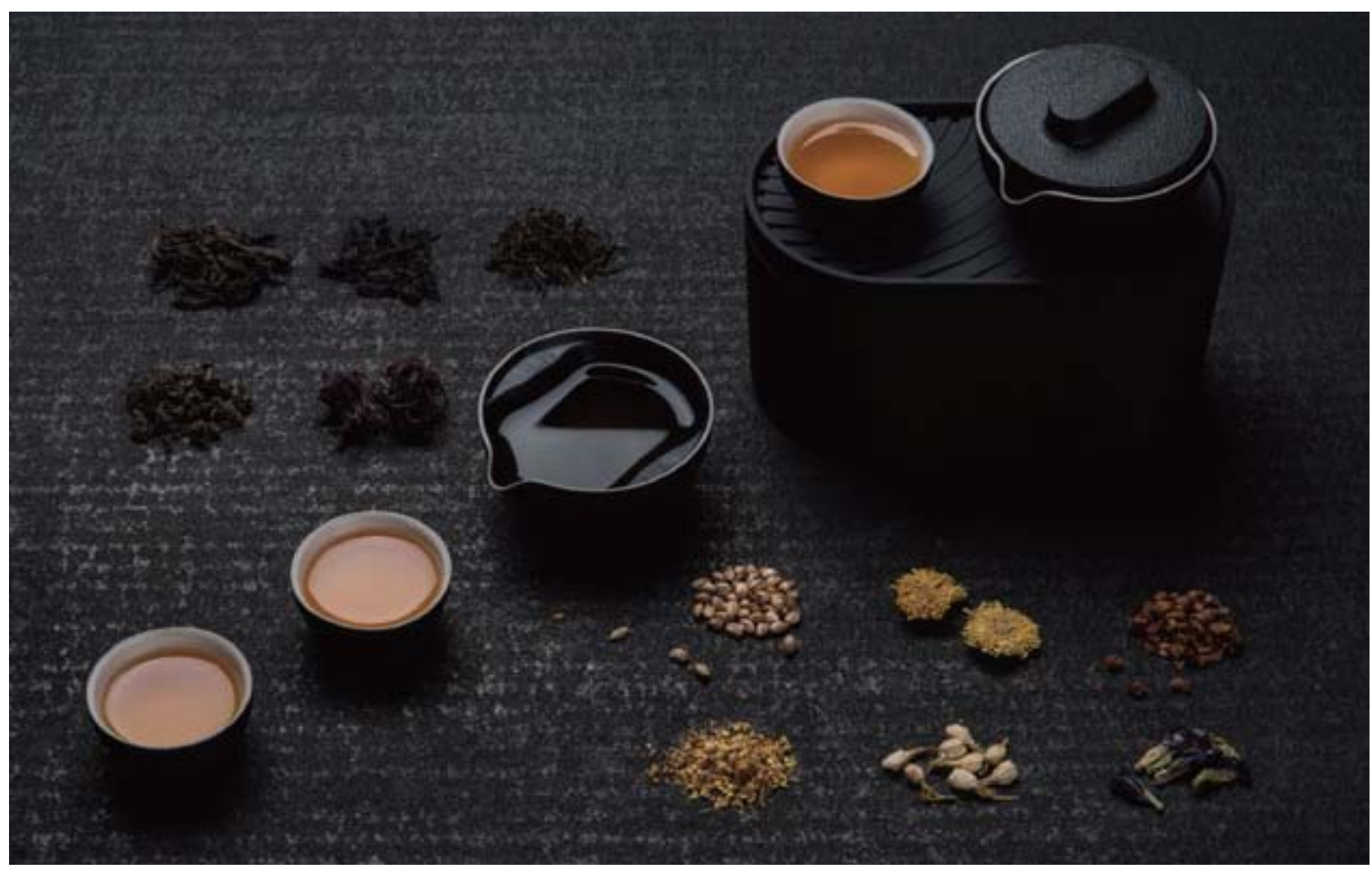

Fig. 8. Mini Tea Set T1. Fabricado por Pertouch, China. Diseñado por BALANCE, Japón. Mini juego de té T1 es un mini set para Kung-Fu té (así llaman los chinos del sur a la ceremonia del té para servir a invitados). Inspirado por el paisaje seco de la pintura china, el diseño obtiene una apariencia minimalista, líneas fluidas y simples sin elementos sobrantes. La tetera tiene forma compacta;por lo tanto se adapta tanto a zurdos como a diestros, y su interior está formado por dos paredes para reducir el calor al 40\%. La bandeja del té está diseñada con 15 canales de drenaje, a ambos lados, para mejorar el proceso a la vez que realza la apariencia del jardín zen. 


\section{Asociación figurativa}

A nivel global, podríamos simplificar, drásticamente quizás, afirmando que las principales corrientes artísticas en las que se desarrolla el arte durante el siglo XX son el Realismo Soviético y el Arte Pop, y después de más de 80 años su influencia sigue vigente en la percepción del pueblo chino. El Realismo Soviético fue la única corriente artística occidental empleada para el retrato de Mao durante su etapa de poder. El Arte Pop, como su propio nombre indica, es el acto de hacer arte popular; es decir, creaciones a partir de imágenes que resultaren familiares y cotidianas. Ambas corrientes comparten su carácter figurativo, y esta característica ha determinado durante décadas los patrones de consumo chinos, dirigiendo los gustos y tendencias para buscar siempre diseños de productos asociados a un objeto real. Es decir, que una silla se adapta mejor al mercado chino si realmente parece una silla, y si a la vez su diseño sugiere a otra figura, como por ejemplo la de un animal, resultará más simpática y atractiva para el consumidor asiático. La asociación es una de las claves en el diseño de producto para el mercado chino.

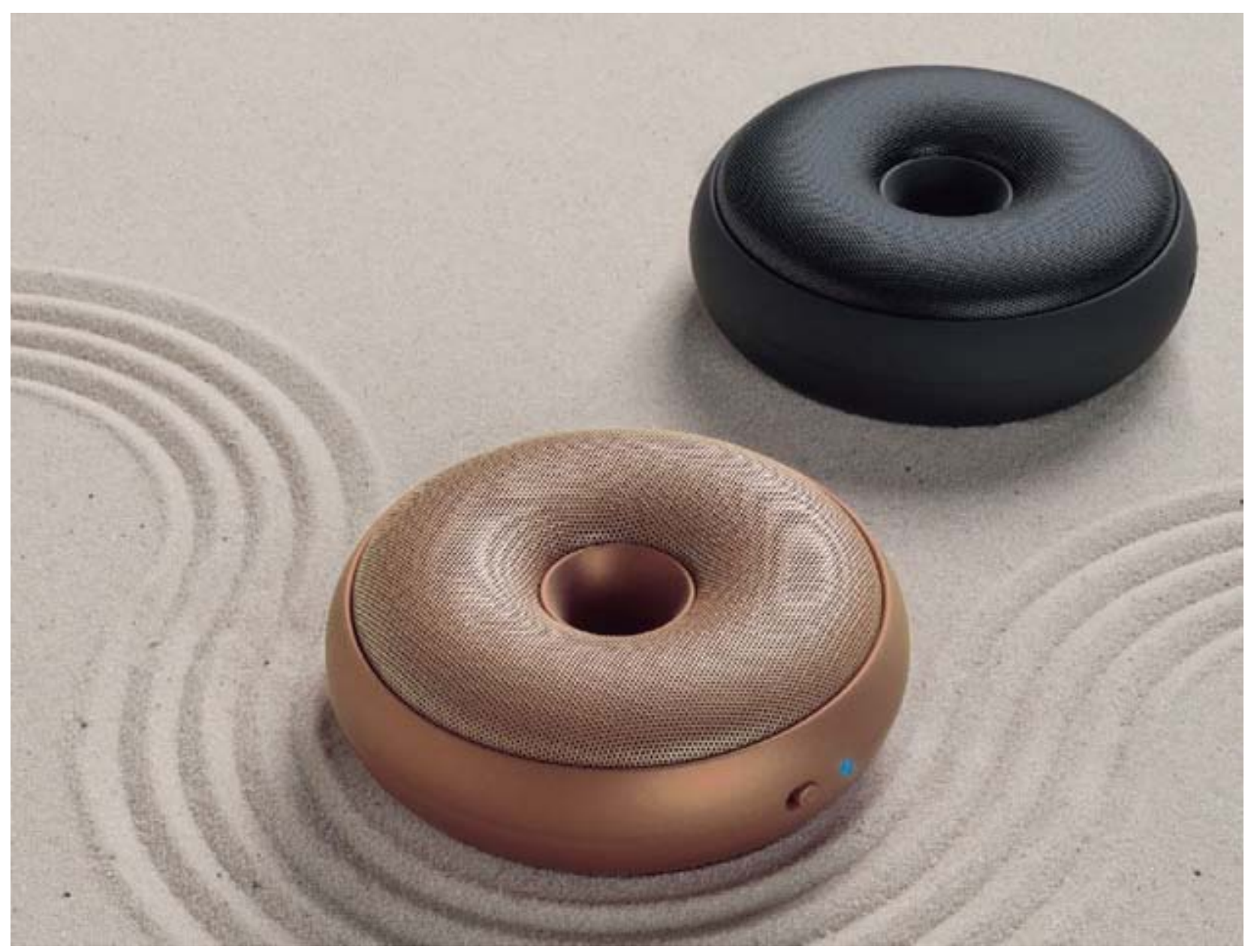

Fig. 9. Altavoces Hoop. Fabricado por LEXON Electronic Commerce Co. Ltd. China. Diseñado por Valentina Del Ciotto \& Simone Spalvieri, Italia. Altavoces de conexión bluetooth, cuya forma redonda da a entender constante movimiento. Se ofrece en diversas gamas de colores, como el azul oscuro, gris, rojo, verde claro o cobre. El diseño concuerda con su filosofía y lleva un cordón de silicona incorporado, para poder colgarlo en vestuario o a otro accesorio y llevarlo consigo. La selección de colores mostrada en la imagen los vincula directamente con un par de donuts. 


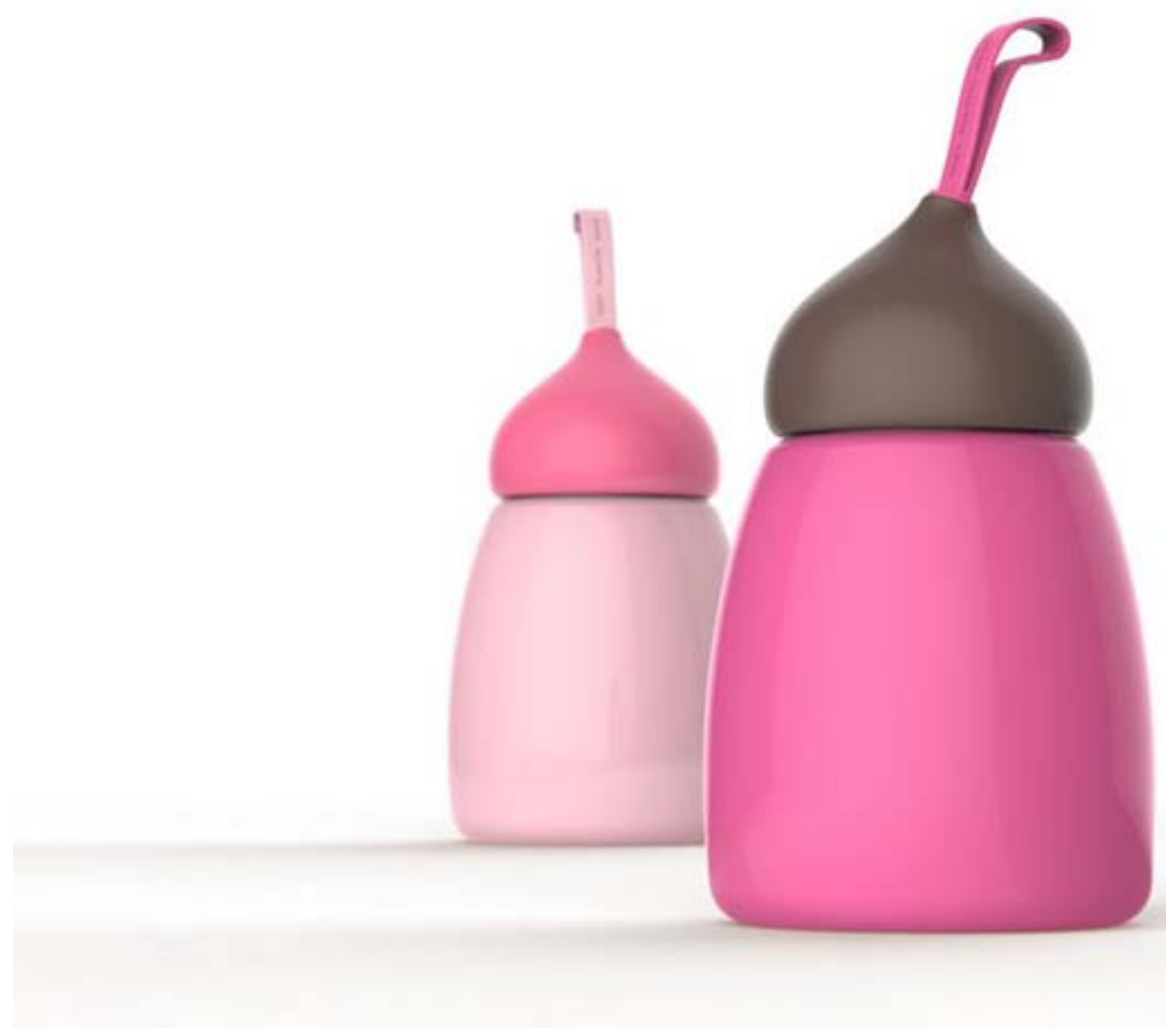

Fig. 10. Haoshi cup. Fabricado y diseñado por Hefei Songshi Trading Co. Ltd. China. El tapón es un homenaje a la forma del clásico chocolate Hershey. Además, el termo Haoshi utiliza la tecnología de micro-drop paint para buscar colores apetitosos como el rosa melocotón o el amarillo mango.

${ }^{1}$ Doctor en Bellas Artes por la Universidad de Málaga, Licenciado en Bellas Artes por la Universidad de Granada, fue el Jefe del Departamento de Diseño de LEXON en China (2014), y actual Supervisor Artístico y Diseñador Jefe para Xiamen AMOYSEN Design Communication. E-mail: nong_ruc@hotmail.com

\section{IMÁGENES}

Figuras 1, 2 y 3 . Fotografías propias.

Figuras 5 y 6. Ofrecidas por AMOYSEN, Red dot in Xiamen. http://www.xidbw.org/

Figuras 4, 7, 8, 9, 10. Ofrecido por AMOYSEN. China Good Design Award http://www.chinagooddesignaward.com/

Revista internacional de investigación, innovación y desarrollo en Diseño • ISSN 1889-433 x

Grupo de investigación Lenguaje Visual y Diseño Aplicado • Plan Andaluz de Investigación • E. Politécnica S. • Universidad de Málaga 